\title{
A Casa da Ópera de Vila Rica através do estudo de duas cartas de João de Souza Lisboa
}

The Opera House of Vila Rica through the study of two letters of João de Souza Lisboa

Mariana Soutto Mayor

Mariana Soutto Mayor Doutoranda do Programa de Pós-Graduação em Artes Cênicas da Escola de Comunicações e Artes da Universidade de São Paulo (USP).

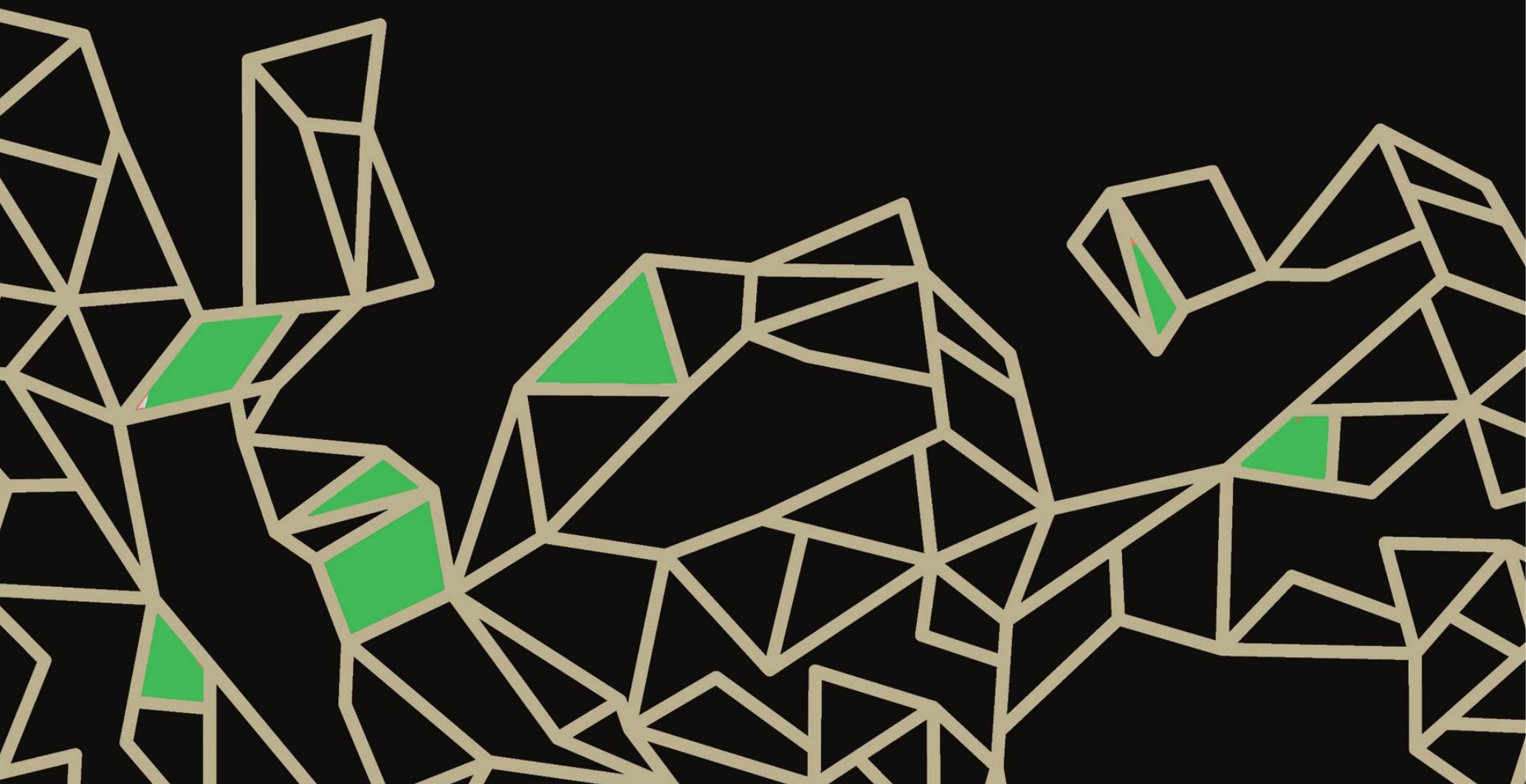




\section{Resumo}

O trabalho pretende investigar alguns pressupostos para o estudo da Casa da Ópera de Vila Rica, a partir da análise de duas cartas do ano de 1770 enviadas pelo contratador João de Souza Lisboa, encontradas no Arquivo Público Mineiro, em Belo Horizonte. O estudo dessa documentação pode fornecer material para a investigação dos motivos materiais e ideológicos da construção da Casa da Ópera, e também sobre as formas de organização e produção do teatro que hoje - em relação aos prédios teatrais existentes - é considerado o mais antigo da América Latina.

Palavras-chave: Casas da Ópera, Teatralidades coloniais, Teatro em Minas Gerais no século XVIII.

\section{Abstract}

This work aims to investigate some assumptions for the study of the Opera House of Vila Rica starting from the analysis of two letters sent by the contractor João de Souza Lisboa in 1770, both of them found in the Public Archive of Minas Gerais in Belo Horizonte. This documentation study can provide elements to investigate the materials and idelogicals motives behind the construction of the Opera House and information of organization and theatrical mode of production of the theater that today, regarding all existent buildings, is considered the oldest one in Latin America.

Keywords: Operas House, Colonial theatricalities, Theatre in Minas Gerais in the 18th century.

A pesquisa sobre as formas teatrais em Minas Gerais no século XVIII passa necessariamente pela análise de fontes documentais. Tanto o estudo sobre as festividades públicas que dominaram o cenário cultural na primeira metade do século XVIII, assim como as casas de ópera construídas, em sua maioria, na segunda metade do mesmo século, esbarram em impasses quando só analisada a bibliografia crítica existente.

Mesmo considerando grandes obras da história do teatro brasileiro de autores como Múcio da Paixão, Galante de Souza, Décio de Almeida Prado, Sábato Magaldi, Lothar Hessel e Georges Readers, Eduardo Cafezeiro 
e, especificamente, sobre Minas Gerais, Affonso Ávila e José de Seixas Sobrinho - que inclusive citam várias fontes documentais - percebe-se que há lacunas históricas a serem preenchidas e que, portanto, é necessário o retorno às fontes primárias em arquivos públicos e privados.

A maior parte da documentação existente sobre as casas da ópera em Minas Gerais, e particularmente sobre a Casa da Ópera de Vila Rica - objeto desse estudo - encontra-se no Arquivo Público Mineiro, em Belo Horizonte, no Arquivo do Museu da Inconfidência, em Ouro Preto, na Biblioteca Nacional, no Rio de Janeiro e, finalmente, no Arquivo da Torre do Tombo, em Lisboa.

Uma das fontes documentais mais importantes no estudo do prédio teatral está em um códice da coleção Casa dos Contos do Arquivo Público Mineiro, composto pela correspondência do contratador João de Souza Lisboa, construtor da Casa da Ópera, no final do século XVIII.

Foi o filólogo português Manuel Rodrigues Lapa, exilado no Brasil pelo regime salazarista, quem primeiro registrou, em artigo intitulado $A$ Casa da Ópera de Vila Rica, de 1968, a importância desse material para o estudo da Casa da Ópera de Souza Lisboa. No texto, o pesquisador cita e comenta trechos de cartas enviadas a agentes do contratador em Minas, Rio de Janeiro e Lisboa, trazendo questões importantes sobre o prédio teatral.

Rodrigues Lapa, com esse pequeno artigo, tornou-se uma das grandes referências no estudo da Casa da Ópera de Vila Rica. As documentações citadas por ele foram estudadas por Curt Lange ${ }^{1}$, e retrabalhadas por Rogério Budasz e Rosana Marreco Brescia, dois importantes pesquisadores da área de musicologia que realizaram estudos recentes sobre as casas da ópera na América Portuguesa².

Em pesquisa ao Arquivo Público Mineiro, pude ler as cartas citadas por Rodrigues Lapa. O conteúdo dos documentos, apesar de já ter sido citado e

1 No acervo Curt Lange, localizado na Universidade Federal de Minas Gerais, há alguns manuscritos em que Curt Lange escreve a Casa da Ópera de Vila Rica. Em um deles, Curt Lange comenta: "Correspondência de João de Souza Lisboa que abrange o longo período do $3^{\circ}$ quarto do século XVIII e que dá conta do vivo interesse do proprietário para dotar à sua empresa de recursos apreciáveis em óperas e solfas, descoberta pelo insigne historiador Manuel Rodrigues da Lapa no A. P. M, vide Minas Gerais, Supl. Literário, 20 I 1968, p. 5." (Cx.23, Série 10.3.16.01).

2 Inclusive Rosana Marreco Brescia, em 2012, lançou o livro É lá que se representa a comédia: a Casa da Ópera de Vila Rica (1770-1822), que cita e estuda muitas fontes documentais sobre o prédio teatral mineiro. 
analisado por outros pesquisadores, trouxe novas perspectivas para a minha pesquisa de doutoramento. Especificamente duas cartas são peças-chave para o entendimento dos modos de organização da Casa da Ópera e é sobre elas que tratarei neste artigo.

\section{O surgimento das casas da ópera na América Portu- guesa}

As casas da ópera representaram uma mudança no fazer teatral na colônia. Até a segunda metade do século XVIII, as festas públicas concentravam as práticas teatrais de Minas Gerais, com funções eminentemente políticas e religiosas. Seguindo modelos festivos europeus e como espetáculos barrocos de enorme apelo e fascínio sensorial, as festas mineiras concentravam uma série de práticas representacionais incluindo cavalhadas, touradas, procissões religiosas, desfiles de alegorias, carros triunfais, poesias, danças, músicas e apresentações de peças teatrais em palcos de madeira, especificamente construídos para as representações.

Com a construção e inauguração das casas da ópera esse cenário se modifica, pois há uma gradativa mudança nas formas e funções teatrais no século XVIII. Com os novos prédios, o teatro assumiria, para além das funções religiosa e política, a função de mercadoria, ao estipular preço de entradas e camarotes. A emergência das casas da ópera não significou o fim das festas públicas, pois elas continuaram sendo organizadas concomitante às temporadas nos teatros.

Décio de Almeida Prado e Sábato Magaldi consideram as casas da ópera como uma inovação teatral que deu início a um teatro regular no Brasil:

Cabe-nos considerar essa inovação um progresso essencial da atividade cênica, sobretudo porque os prédios teatrais foram utilizados por elencos mais ou menos fixo, com certa constância no trabalho. (MAGALDI, 1997, p. 27)

Para esses autores, a regularidade da produção teatral estaria relacionada com a existência de uma estrutura complexa de formação de companhias teatrais, repertórios, público pagante, maquinarias, músicos para a orquestra 
e empresários que intermediariam as temporadas das companhias com o proprietário do prédio teatral. Décio de Almeida Prado ainda escreveria que:

Se, no entanto, para conferir ao conceito (teatro) a sua plena expressão, exigirmos que haja uma certa continuidade de palco, com escritores, atores e público relativamente estáveis, então o teatrão só terá nascido alguns anos após a Independência, na terceira década do século XIX. (PRADO, 1993, p. 15)

Considerando os estudos de Prado e Magaldi, as casas da ópera significaram um "progresso teatral" e possuíam "certa constância no trabalho". Somado a essa interpretação ainda podemos considerar o fato de que esses prédios teatrais não surgiram sem contradições: eles oscilariam entre uma forma amadora e profissional; entre a formação de um mercado teatral e a manutenção de formas societárias aristocráticas. Portanto, para entendermos o fenômeno das casas da ópera, é preciso estudar quais são os impasses e as dificuldades de se manter uma regularidade na produção dessas novidades teatrais do século XVIII em Minas Gerais.

O objeto de estudo da nossa pesquisa, a Casa da Ópera do contratador João de Souza Lisboa, começou a ser construída no ano de 1769 e foi inaugurada no dia 7 de junho de 1770 - dia do aniversário do rei de Portugal D. José I - com a apresentação da ópera de Cláudio Manuel da Costa, São Bernardo ${ }^{3}$.

A Casa da Ópera do contratador não foi uma exclusividade em Minas Gerais, muito menos no território da América Portuguesa. Rogério Budasz, no livro Teatro e música na América Portuguesa”, detalha casas da ópera em atividade em diferentes cidades coloniais, desde pelo menos 1719. Há documentos que comprovam a existência de casas da ópera no Rio de Janeiro, Belém, Salvador, Porto Alegre e São Paulo.

3 Vila Rica já havia conhecido um prédio teatral como esse. Há documentos de 1751 que citam a demolição da fachada de uma Casa da Ópera (a primeira de que se tem notícia) para a apresentação de dramas musicais na festividade de Aclamação de D. José $I$. Fatalmente, pouco tempo depois, pela destruição da parede frontal, o prédio acabou desmoronando. O teatro de João de Souza Lisboa seria, portanto, a segunda Casa da Ópera de Vila Rica. Porém, a diferença em relação à primeira é que o teatro de 1770 permaneceu ativo, com temporadas durante todo o final do século XVIII e por todo século XIX, municipalizando-se no século XX. Hoje, este pequeno teatro é conhecido como a Casa da Ópera mais antiga da América Latina. Cf. Budazs (2008, p. 230). 
O modelo que a Casa da Ópera de Vila Rica seguiu era proveniente de Portugal, onde os teatros públicos eram construídos pela iniciativa privada e alugados para empresários que se ocupavam da produção de espetáculos, do uso comercial das salas e, consequentemente, da gestão comercial do teatro. Segundo a pesquisadora Rosana Brescia, os teatros públicos portugueses desenvolveram suas atividades sem interferência do Estado, salvo quando tinham de pagar alguns impostos (BRESCIA, 2010).

Não só o modo de produção, mas tanto o repertório quanto as formas de representação estavam vinculadas ao teatro português. Para se ter uma ideia, desde sua inauguração, em 1770, até 1793 foram apresentadas as peças de Pietro Metastasio: José no Egito, Jogos Olímpicos, Alexandre na Índia, Semíramis e Herói da China; de Carlo Goldoni: Feira de Marmantil e Mundo da lua; e de Voltaire: Zaíra, Mafoma e Sezostris no Egito. Todos esses textos foram publicados em formato de cordel para serem vendidos nas ruas portuguesas, com adaptações dramatúrgicas ${ }^{4}$. Todo esse material foi trazido e adaptado para as representações em Vila Rica.

\section{Novas perspectivas sobre a construção da Casa da Ópera através das cartas de João de Souza Lisboa}

No dia 31 de julho de 1770, o contratador João de Souza Lisboa enviou uma carta ao alferes João Batista de Carvalho. Após uma longa descrição de afazeres, negócios e contas, o contratador comenta a seguinte informação num pequeno parágrafo ao final da carta:

estou aqui encarregado de huma Caza de Opra que me mandaram fazer e a fiz que me chegou a dezasseis mil cruzados e agora não tenho mais remédio que suprir com o que he preciso para ella 5 .

A informação de que "mandaram fazer" uma Casa da Ópera complexifica a posição de João de Souza Lisboa à frente de seu negócio teatral. Lisboa

4 Há um importante acervo de teatro de cordel português no Centro de Estudos Teatrais Jorge de Faria, da Universidade de Coimbra, e na biblioteca da Fundação Calouste Gulbenkian, em Lisboa.

5 Fonte manuscrita: Arquivo Público Mineiro (CC 1206, fl. 2v e 3). 
era um dos maiores contratadores do final do século XVIII em Minas Gerais, comparado a João Rodrigues de Macedo e João Fernandes de Oliveira. Considerados "sócios temporários da Coroa", esses grandes negociantes atuavam como braços do aparelho estatal, especialmente em relação ao trato de mercadorias no domínio ultramarino.

Para ser um grande contratador era necessário não apenas capital acumulado, mas também, e talvez principalmente, estabelecer uma rede de ótimas relações com grandes comerciantes, com os homens de negócio da Praça de Lisboa, militares e autoridades políticas da capitania locais e na Corte.

A trajetória de Lisboa foi modelar nesse sentido. Desde a assinatura do seu primeiro contrato, em 1757, Lisboa chegou a obter um hábito da Ordem de Cristo, símbolo de maior nobilitação da época. A construção de sua Casa da Ópera veio para coroar uma década de grandes contratos e sucesso em seus negócios (além de contratador, Lisboa tinha outros empreendimentos, como a venda de mercadorias, mineração, criação de gado, sesmarias, posse de homens escravizados e empréstimos a juros).

Segundo Luiz Antonio de Araujo, na década de 1760, João de Souza Lisboa estava em seu apogeu não apenas como grande negociante, mas também por sua condição de prestígio na sociedade mineira como Coronel do Regimento da Nobreza Privilegiada de Vila Rica e Cavaleiro Professo na Ordem de Cristo. E, mesmo preso em 1763, pelo não pagamento de dívidas, Lisboa continuaria a contabilizar créditos em sua conta corrente ${ }^{6}$.

O dado de que "o mandaram fazer" a Casa da Ópera redimensiona Lisboa em relação a determinações superiores a ele. Em terras coloniais, onde há hierarquias rígidas e sociabilidades herdeiras do Antigo Regime europeu, a ordem de uma autoridade política não poderia ser descartada por mais rico e bem-relacionado que fosse o contratador. Mas quem poderia ter ordenado a construção da Casa da Ópera? E por que essa informação é importante para o estudo do local?

6 Nesse período, João de Souza Lisboa ainda foi proprietário de casas de aluguel (no mínimo doze casas em Vila Rica e uma em Mariana), adquiriu gado e tornou-se sócio de uma mineração no Morro Vermelho do Caeté. Sua prisão devido a uma suposta falência foi aparente, pois Lisboa não deixou de atuar em Minas Gerais como o grande negociante de antes. Foi somente em 1778, após o falecimento do contratador, que a Coroa decretou a intervenção de sua Casa Comercial, estabelecendo uma junta para administrar as dívidas e créditos. Cf. Araujo (2002, p. 146). 
O filólogo Manuel Rodrigues Lapa, em artigo já mencionado anteriormente, revela uma possibilidade:

Por aqui se pode concluir que a construção do teatro fora uma imposição do Governador, a troco, sem dúvida, de concessões ao rendeiro, que não olvidava, para além de tudo os seus legítimos interesses; e que a 31 de julho já estava concluído [...]. (LAPA, 1963, p. 5)

O governador ao qual Rodrigues Lapa se refere é o nobre português José Luís de Meneses Castelo Branco e Abranches, Conde de Valadares, que em 1768 tomou posse como governador-geral da Capitania de Minas Gerais.

A hipótese de Rodrigues Lapa nos revela indícios do que poderia ter acontecido. Afinal, quem mais poderia ordenar a um rico e prestigioso contratador construir um prédio teatral senão a maior autoridade política de uma região visada e controlada pela Coroa na América Portuguesa, como Vila Rica?

Se tomarmos como exemplo outras casas da ópera na América Portuguesa para comparação, a presença de governadores e de membros das câmaras locais mediando a construção de prédios teatrais é uma constante. Segundo Rogério Budasz (2008), em 1767, o governador da Província de São Paulo, Morgado de Matheus, esteve envolvido na construção de uma Casa da Ópera. Em Belém, em 1755, outra Casa da Ópera foi construída a pedido do governador João Pereira Caldas. Em Salvador, há documentos que provam a construção de um tablado de madeira na casa da Câmara, sob ordem do vice-rei, mais ou menos por volta de 1728, mantendo suas atividades por quatro anos.

A participação de autoridades políticas coloniais na construção de prédios teatrais também pode ser entendida dada a função das câmaras municipais em se responsabilizar por um calendário festivo cívico e religioso na América Portuguesa, por determinações da Coroa. As práticas representacionais na colônia se concentravam em sua grande parte nas festividades públicas e, mesmo sendo uma festa religiosa, como Corpus Christi, por exemplo, a câmara fazia parte de sua organização. Ou seja, a produção cultural na colônia passava por iniciativas das autoridades políticas locais que, por sua vez, representavam de forma mais ou menos enfática o poder da Coroa. 
Dada esta hipótese, é possível pensar que, para além de interesses econômicos e políticos de Souza Lisboa com a construção da Casa da Ópera, havia um projeto cultural de parte da elite intelectualizada da vila, que seguia, ao mesmo tempo, ideais iluministas e aristocráticos do teatro português da segunda metade do século XVIII.

Para se ter uma ideia, dois anos antes da construção da Casa de Ópera, no dia 4 de setembro de 1768, o poeta e advogado Claudio Manuel da Costa, que anos depois estaria envolvido na Inconfidência Mineira, organizou no palácio do Conde de Valadares, recém-empossado governador da capitania de Minas Gerais, um recital de poesias para lançar as bases da sua Arcádia Ultramarina.

Foi nessa noite que o poeta ofereceu para o próprio governador o cargo honorífico de custódio sob o nome de Pastor Daliso da Arcádia Ultramarina ${ }^{7}$. Pouco tempo depois, no dia 5 de dezembro do mesmo ano, Claudio Manuel da Costa voltou ao palácio do governador para a encenação de seu drama musical o parnaso obsequioso, especialmente para celebrar o aniversário do governador-geral. Apolo, Mercúrio e as musas Calíope, Melpomene, Tália e Clio saudavam o governador, seguindo o modelo dramatúrgico do italiano Pietro Metastasio - autor de enorme sucesso na Europa no século XVIII.

Formaram-se nesse momento relações importantes que determinaram também a construção da Casa de Ópera. Não à toa que a primeira peça a ser encenada no teatro recém-inaugurado, em 1770, ainda sob a administração de João de Souza Lisboa, seja da autoria de Claudio Manuel da Costa: o drama musical religioso São Bernardo ${ }^{8}$. E não à toa também que o governador tenha se engajado em atividades literárias do movimento que futuramente ficou conhecido como "arcádia mineira".

É provável também que João de Souza Lisboa tivesse relações com Claudio Manuel da Costa e com o conde de Valadares, e que no mínimo apreciasse a forma teatral e simpatizasse com o movimento literário. O cuidado

7 Arcádia Ultramarina foi o nome da Academia Literária fundada, por volta de 1769, por Cláudio Manuel da Costa em Vila Rica.

8 Até agora não foram encontrados resquícios dessa dramaturgia. Os documentos que fazem menção à obra são cartas de João de Souza Lisboa ao capitão José de Sousa Gonçalves, de São João del Rey, onde Lisboa menciona o roubo de partituras que estavam em sua casa, dentre elas um ato da ópera São Bernardo, de Claudio Manuel da Costa. 
de Souza Lisboa com o sua Casa da Ópera aparece no trecho da mesma carta que citamos. Ele diz que gastou "dezasseis mil cruzados" e que nesse momento não tem "mais remédio que suprir com o que he preciso para ella" Ou seja, Lisboa fez um grande investimento e está apreensivo sobre como mantê-lo ativo.

Com a Casa da Ópera era possível lucrar com as entradas e com os aluguéis de camarote ${ }^{10}$, mas, como organizar um repertório, contratação de atores e músicos, elaboração de cenários, adereços e figurinos?

Souza Lisboa seguiu uma prática comum nos teatros públicos portugueses e de outras casas da ópera na América Portuguesa ao arrendar o seu prédio teatral para empresários que se responsabilizariam pela manutenção do teatro. O que é curioso no caso de Lisboa é que ele não deixou de participar ativamente da escolha de repertório e de atores e músicas para a Casa da Ópera até a sua morte, em 1778. Entre as suas cartas há algumas endereçadas a seus agentes na colônia e em Lisboa pedindo por solfas, partituras e peças teatrais, além de haver outras em que ele procura atores, comenta sobre novas contratações etc. Outro documento interessante para ser analisado aqui é uma carta de Lisboa ao Reverendo Dr. João Caetano Pinto, residente em Sabará, de 13 de julho de 1770, em que o remetente, depois de discorrer sobre a questão de pagamentos e negócios, escreve no final da carta:

E também terá chegado a notícia de vossa mercê que mandei fazer aqui huma Caza de Opera que se acha concluída mas o melhor the falta que são algumas figuras para representar o gracioso para os papeis de bobo se um ahy tiver notícias de algum sogeito que tenha o exercitado em operas e ainda não tenha propriedade para representar eu careso dellas ${ }^{11}$.

9 Fonte manuscrita: Arquivo Público Mineiro (CC 1206, fl. 2v e 3).

10 Brescia reitera a importância do teatro no século XVIII como espaço de sociabilidade e de relacionamentos políticos entre a elite local na apresentação de seu livro: "Aspecto fundamental para a compreensão da plena importância que os públicos assumiram durante os séculos XVIII e XIX é a sua vocação em converter-se no lugar mais idôneo para o estabelecimento de relações políticas e sociais das mais variadas. No caso da capital das Minas Gerais, assume importância o fato de que o teatro era o único espaço público de convivência fora do âmbito religioso existente nos Setecentos. Como consequência, entre seus espectadores figuravam as mais importantes personalidades da sociedade mineira de finais do século: ouvidores, advogados, procuradores, contratadores, mineradores, poetas, os próprios governadores da capitania, e alguns inconfidentes" (BRESCIA, 2012).

11 Fonte manuscrita: Arquivo Público Mineiro (CC 1205, fl. 28). 
Duas informações nos chamam a atenção nesse trecho da carta. A primeira é a rede de contatos do contratador envolvendo um padre de Sabará. Como é sabido, esta outra vila mineira teve também uma Casa da Ópera na segunda metade do século XVIII. Segundo o livro O Teatro em Sabará, de José de Seixas Sobrinho (1961), há um documento da Câmara municipal de 1783 que cita uma contenda jurídica envolvendo um advogado sobre a contabilidade do ouro que "o administrador da Casa da Ópera poz em juízo, das terras que comprou aos herdeiros" (SOBRINHO, 1961).

A citação de um "administrador da Casa da Ópera" faz supor a existência de um prédio teatral em Sabará antes de 1783. Não se sabe ao certo quando teria sido inaugurado, mas a sua existência no final do século XVIII nos revela uma possível teia de relações entre teatros, em que atores e músicos, assim como peças de teatro e partituras musicais, circulavam por entre as casas da ópera de Minas Gerais.

É interessante citar aqui também que o grande pesquisador Affonso Ávila, no livro O teatro em Minas Gerais, de 1978, considera ainda a existência de um prédio teatral construído em Arraial do Tejuco, entre 1753-1771, o chamado "Teatrinho de bolso da Chica da Silva", onde foram encenadas peças do dramaturgo Antônio José da Silva; outra Casa da Ópera em Paracatu, por volta de 1780, e mais uma em São João del Rey, entre 1780-1808 (ÁVILA, 1978).

Esses prédios teatrais em atividade na segunda metade do século XVIII, em Minas Gerais, podem nos levar a pensar na existência de um pequeno circuito teatral na capitania. Entretanto, a demanda de artistas e repertórios inclusive há um caso interessantíssimo do roubo da ópera São Bernardo, de Cláudio Manuel da Costa, relatado pelo próprio Souza Lisboa em carta - não necessariamente afirma um processo de profissionalização do teatro ou uma institucionalização dessa atividade cultural.

O que nos leva a pensar nesse funcionamento ora amador, ora profissional, que possui elementos da cultura burguesa, mas também a permanência da cultura aristocrática, é o seguinte trecho da carta: "se um ahy tiver notícias de algum sogeito que tenha o exercitado em operas e ainda não tenha se tenha propriedades"12.

12 Fonte manuscrita: Arquivo Público Mineiro (CC 1205, fl. 28). 
Lisboa tinha a necessidade de contratar um ator que desempenhasse a função de "gracioso"13 no palco de sua Casa da Ópera, entretanto, esse ator poderia ter ou não experiência no ofício da representação de óperas. Ou seja, ele poderia ser um ator em formação ou mesmo um amador que nunca tenha representado esse tipo de personagem. Estamos diante, portanto, de uma estrutura ora profissional, ora amadora, que carece de elementos importantes para estabelecer a continuidade das temporadas da Casa da Ópera do ponto de vista da formação de um mercado teatral regular.

A Casa da Ópera de Souza Lisboa viveria, ao longo do final do século XVIII, pendulando entre a expectativa de se formar em Vila Rica um teatro regular e as intermitências da realidade local de colônia. E, pensando sobre a realidade colonial, é importante mencionar que a maior parte dos atores e atrizes contratados para as representações, assim como os músicos das orquestras, eram negros e mestiços. O palco do teatro estava marcado também pela particularidade histórica e social perversa que estruturou a colonização da América portuguesa: o escravismo.

As cartas de João de Souza Lisboa mencionadas neste trabalho apresentam questões importante para se pensar as motivações materiais e ideológicas na construção da Casa da Ópera e suas formas de organização. $A$ leitura das cartas deve ser feita em relação a toda a trajetória de vida do contratador e, nesse sentido, o retorno ao Arquivo Público Mineiro é fundamental para inclusive encontrar novas perspectivas de estudo a partir da leitura dos documentos do códice.

A análise dessa documentação como parte da pesquisa sobre a produção teatral da Casa da Ópera de Vila Rica no final do século XVIII é um estudo de caso que pode nos ajudar a entender melhor as formas e funções do teatro colonial desse período no Brasil, e assim compreender melhor as relações de nosso passado colonial com a produção contemporânea.

13 Personagem da comédia nova espanhola, o gracioso é conhecido como o criado cômico. Figura importante nas comédias de Capa e espada, o gracioso fazia muito sucesso no teatro português. No século XVIII, peças de teatro francesas e italianas foram adaptadas "ao gosto português." Uma dessas adaptações era a entrada do personagem "gracioso". 


\section{Referências bibliográficas}

ÁVILA, A. O teatro em Minas Gerais nos séculos XVIII e XIX. Ouro Preto: Secretaria Municipal de Cultura e Museu da Prata, 1978.

ARAUJO, L. A. S. Contratos e tributos nas Minas setecentistas: o estudo de um caso - João de Souza Lisboa (1745-1765). 2002. 176 f. Dissertação (Mestrado em História) - Programa de Pós-graduação de História, Instituto de Ciências Humanas e Filosofia, Universidade Federal Fluminense, Niterói, 2002.

BRESCIA, R. M. É lá que se representa a comédia: a Casa de Ópera de Vila Rica (1770 - 1822). Jundiaí: Paco Editorial, 2012.

C'est là que I'on joue la comédie: les Casas da Ópera en Amérique Portugaise (1719-1819). 2010. 768 f. Tese (Doutorado em História Moderna e Contemporânea e Ciências Musicais) - Universidade de Paris IV, Universidade Nova de Lisboa, Paris, 2010.

BUDASZ, R. Teatro e música na América Portuguesa: ópera e teatro musical no Brasil (1700-1822): convenções, repertório, raça, gênero e poder. Curitiba: DeArtes, Universidade Federal do Paraná, 2008.

LAPA, M. R. A Casa de Ópera de Vila Rica. Suplemento Literário do Jornal Minas Gerais, 20 jan. 1968, p. 5.

MAGALDI, S. Panorama do teatro brasileiro. São Paulo: Global, 1997.

PRADO, D. A. Teatro de Anchieta a Alencar. São Paulo: Perspectiva, 1993.

SOBRINHO, J. S. O teatro em Sabará: da Colônia à República. Belo Horizonte: B. Alvares, 1961.

Recebido em 24/09/2017

Aprovado em 06/11/2017

Publicado em 26/12/2017 